(2) Open Access Full Text Article

\title{
Sustained maintenance of clinical remission after adalimumab dose reduction in patients with early psoriatic arthritis: a long-term follow-up study
}

This article was published in the following Dove Press journal:

Biologics: Targets and Therapy

II July 2012

Number of times this article has been viewed

\section{Fabrizio Cantini \\ Laura Niccoli \\ Emanuele Cassarà \\ Olga Kaloudi \\ Carlotta Nannini}

Division of Rheumatology,

Misericordia e Dolce Hospital

of Prato, Prato, Italy
Correspondence: Fabrizio Cantini Rheumatology Division, Ospedale Misericordia e Dolce, Prato, Piazza Ospedale, I, 59100, Prato, Italy $\mathrm{Tel}+390574434572$

Fax +39057443442I

Email fbrzcantini@gmail.com
Purpose: The primary purpose of this study was to evaluate the proportion of psoriatic arthritis (PsA) patients maintaining clinical remission after adalimumab (ADA) dose reduction compared with patients with rheumatoid arthritis. Secondary purposes include evaluating the proportion of PsA patients who achieve remission, the duration of remission after ADA dose reduction, time to relapse, psoriasis course, and the frequency of adverse events at the end of follow-up.

Methods: This was a single-center, prospective, follow-up, case-control study of 76 consecutive patients ( 35 females, 41 males; mean age $46 \pm 10.2$ years) who met the classification criteria for psoriatic arthritis and required anti-tumor necrosis factor therapy according to Group for Research and Assessment of Psoriasis and Psoriatic Arthritis recommendations. The 76 patients were compared with 55 patients (40 females, 15 males; mean age $50 \pm 11.6$ years) who satisfied the American College of Rheumatology criteria for rheumatoid arthritis and received the same treatment. Case patients and controls were recruited from January 2008 to December 2010. At baseline, PsA patients and controls received $40 \mathrm{mg}$ of ADA every other week, usually with methotrexate (10 to $20 \mathrm{mg} /$ weekly). In the presence of clinical remission, ADA dose was reduced to $40 \mathrm{mg}$ every 4 weeks in both groups.

Results: Fifty-three of the 76 (69.7\%) PsA patients and 17 of the $55(30.9 \%)$ rheumatoid arthritis $(P<0.019)$ controls achieved remission after a mean time of $5.1 \pm 1.2$ and $6.3 \pm 1.6$ months, respectively ( $P=$ nonsignificant). After halving the dose of ADA, 47 of the $53(88.6 \%)$ PsA patients and three of the $17(17.6 \%)$ controls maintained remission $(P=0.016)$ over a mean follow-up period of $28.9 \pm 8.4$ and $24.2 \pm 6.4$ months, respectively. No significant changes in Psoriatic Arthritis Severity Index scores were observed. The mean time to relapse was $8.3 \pm 3.4$ months in six case patients and 7.2 \pm 4.2 in 14 controls ( $P=$ not significant $)$. No serious adverse events occurred in either group.

Conclusion: Clinical remission is possible in a high percentage of patients with early PsA receiving ADA. Such remission is maintained in a high proportion of subjects after ADA dose halving, with relevant advantages in terms of patient compliance, drug-exposure risk, and economic burden.

Keywords: psoriatic arthritis, anti-TNF, adalimumab, remission, dose reduction

\section{Introduction}

Psoriatic arthritis (PsA) has long been considered a benign disease, although several follow-up studies have demonstrated an aggressive course with development of joint erosions and deformities in up to $70 \%$ of cases. ${ }^{1}$ PsA is characterized by three main patterns of articular involvement: peripheral oligo-polyarthritis without axial involvement, isolated psoriatic spondylitis, and concurrent involvement of peripheral and axial articular structures. ${ }^{2}$ 
Recently, the Group for Research and Assessment of Psoriasis and Psoriatic Arthritis ${ }^{3}$ and an Italian experts committee $^{4}$ developed treatment recommendations based on a literature review. Anti-tumor necrosis factor (TNF) $\alpha$ agents are recommended for the treatment of peripheral PSA that is resistant to traditional disease modifying anti-rheumatic drugs, for PsA spondylitis that fails to respond to nonsteroidal anti-inflammatory drugs (NSAIDs), and for patients with dactylitis and enthesitis who do not improve with NSAIDs and local corticosteroid injections.

Owing to the evidence of efficacy provided by randomized clinical trials, ${ }^{5-8}$ four anti-TNF $\alpha$ agents - etanercept (Enbrel ${ }^{\circledR}$, Immunex Corporation [a wholly owned subsidiary of Amgen, Inc], Seattle, WA), adalimumab (ADA) (Humira ${ }^{\circledR}$, Abbott Laboratories, Abbott Park, IL), infliximab (Remicade ${ }^{\circledR}$, Centocor, Malvern, PA), and golimumab (Simponi ${ }^{\circledR}$, Centocor Ortho Biotech Inc and Schering-Plough Corporation, PA) - are currently licensed in Italy for the treatment of resistant PsA.

A fully humanized monoclonal anti-TNF $\alpha$ antibody that is usually administered subcutaneously at a dose of $40 \mathrm{mg}$ every other week (eow), ADA was licensed for the treatment of PsA by the Italian Regulatory Authorities in 2005. Evidence regarding the effectiveness of ADA in controlling the signs and symptoms of PsA and in slowing/ arresting the radiographic damage of its different clinical patterns was provided by the Adalimumab Effectiveness in Psoriatic Arthritis Trial ${ }^{7}$ and its long-term extension phase reports. ${ }^{9,10}$ At week 24 of this trial, ${ }^{7} 57 \%$ of the ADA group were American Rheumatism Association (ACR) 20 responders compared with $15 \%$ of the placebo group $(P<0.001)$; the ACR 50 and ACR 70 response rates were significantly higher in the ADA-treated patients. None of the previously mentioned ADA studies ${ }^{7,9,10}$ focused on the frequency of clinical remission of PsA.

Similar to other biologics, ADA represents an expensive therapy with a heavy economic burden for the health care systems of all countries. Consequently, we believe that every ethical strategy effective at reducing cost with no worsening of patient quality of life would be of great value.

In this view, we designed a prospective, follow-up, casecontrol study to evaluate the proportion of early PsA patients treated with ADA who maintain clinical remission after drug dose reduction.

\section{Patients and methods} Study design

This was a prospective, follow-up, case-control study.

\section{Case patients}

Case patients were consecutive new outpatients fulfilling the classification criteria for psoriatic arthritis ${ }^{11}$ with a disease duration of less than 24 months who required anti-TNF $\alpha$ therapy according to the Group for Research and Assessment of Psoriasis and Psoriatic Arthritis recommendations $^{3}$ and who received ADA. Patients were observed between January 2008 and December 2010 at the Rheumatology Division of the Hospital of Prato, Italy. PsA patterns and clinical manifestations were defined as previously reported..$^{2,13-15}$

\section{Controls}

Control patients were consecutive new outpatients meeting the 1987 revised criteria of the ACR for the classification of rheumatoid arthritis (RA) ${ }^{12}$ who were treated with ADA. Patients were observed over the same period as the case patients.

\section{Primary goal}

The primary goal of the study was to evaluate the proportion of PsA patients maintaining clinical remission after ADA dose reduction compared with patients with RA.

\section{Secondary goals}

The secondary goals of the study were to evaluate the proportion of PsA patients who achieve clinical remission, the duration of remission after ADA dose reduction, time to relapse, skin disease changes, and the frequency of adverse events.

\section{Exclusion criteria}

Patients with contraindications to the use of traditional disease modifying anti-rheumatic drugs and anti-TNF $\alpha$ drugs were excluded from the study.

\section{Disease remission}

To define clinical remission in PsA patients, we used the previously reported criteria ${ }^{16}$ based on the absence of fatigue and pain (score $\leq 10$ by visual-analogue scale 1 to $100 \mathrm{~mm}$ ), peripheral and axial articular symptoms (including tendons and entheses), extra-articular features, and normality of acutephase reactants. Patients with PsA spondylitis with a Bath Ankylosing Spondylitis Disease Activity Index score $\leq 4^{17}$ in the absence of articular, tenosynovial, and entheseal manifestations and normality of acute-phase reactants were considered in remission. Remission in controls with RA was defined by a disease activity score $\leq 2.6 .^{18}$ 
Patients of both groups treated with ADA alone or with methotrexate (MTX) were considered in clinical remission if satisfying the previously described criteria and without taking any additional drugs, including NSAIDs and CS for at least two consecutive visits.

\section{Relapse}

Patients and controls were considered as relapsing in the case of the recurrence of any articular or extra-articular clinical manifestations occurring independently on the acute-phase reactants values.

\section{Treatment regimen}

ADA was prescribed at the dose of $40 \mathrm{mg}$ subcutaneous injections eow, usually with MTX at the dose of 10/weekly, both in case patients and in controls. MTX dose escalation to $20 \mathrm{mg}$ /weekly was allowed in cases of unsatisfactory clinical response. In case of MTX intolerance, ADA was given alone.

In PsA patients and controls achieving and maintaining clinical remission for at least 6 months, ADA dose was reduced to $40 \mathrm{mg} / \mathrm{monthly}$ and patients were followed up over time. MTX was continued at stable doses. In case of relapse, patients returned to ADA $40 \mathrm{mg} /$ eow.

\section{Outcome measures}

At baseline and at every follow-up visit, all PsA patients and controls were evaluated for the remission criteria as the primary outcome measure.

Secondary outcome measures were disease activity scores, number of tender and swollen joints, number of painful entheses, number of digits showing dactylitis, inflammatory spinal pain, erythrocyte sedimentation rate and C-reactive protein, and Psoriatic Arthritis Severity Index. ${ }^{19}$

\section{Follow-up}

Each patient received follow-up by the same rheumatologist who had done the first visit; follow-up visits were scheduled at baseline and every 3 months. Control visit intervals were shortened in the case of urgent clinical problems, and all patients were instructed to call the center in presence of worsening of previous arthritis, additional joint involvement, extra-articular manifestations onset, and adverse events.

At each visit, patients had a complete physical examination including all previously listed outcome measures. Moreover, routine blood examinations including erythrocyte sedimentation rate, C-reactive protein, rheumatoid factor, complete blood cell count with differential count, renal and liver function tests, and antinuclear antibodies were carried out. All clinical and laboratory data were recorded in an electronic patient chart.

\section{Adverse events}

All patients were monitored for clinical and laboratory evidence of adverse events, which were classified as mild (transient and easily tolerated), moderate (subject discomfort with interruption of usual activities), or severe (incapacitating or life threatening). The date of last visit constituted the end of the follow-up period, which was extended to December 2011.

The local ethics committee reviewed and approved the study protocols. Before entering the trial, each patient was informed of the nature, duration, and purpose of the study, as well as of all the potential benefits and drawbacks that could be expected. All participants gave written informed consent.

\section{Statistical analysis}

Descriptive statistics and statistical differences were calculated using SPSS statistical package version 11 for Windows (SPSS Inc, Chicago, IL).

Wilcoxon's matched pairs signed-rank test was used to measure the changes from baseline; $t$-test for continuous variables and chi-square test for nominal variables were used to calculate the differences between the study patients and controls. $P$ values $<0.05$ were considered significant.

\section{Results}

Over the 3-year study period, 76 PsA patients and 55 RA controls requiring anti-TNF therapy were treated with ADA. The baseline demographic and clinical characteristics of PsA cohorts and controls are summarized in Table 1. As shown in Table 2, of the 76 PsA patients, 53 (69.7\%) achieved clinical remission compared with 17 (30.9\%) out of 55 controls with RA $(P<0.001)$. Remission was recorded in 14 of the $49(28.5 \%)$ rheumatoid factor positive patients and in three of six (50\%) rheumatoid factor negative RA patients, with no significant statistical difference $(P=0.753)$. The mean time to achieve the remission was $5.1 \pm 1.2$ months for PsA patients and $6.3 \pm 1.6$ months for controls $(P=$ not significant). The remission rates in peripheral, axial, and mixed PsA were $71.1 \%, 71.4 \%$, and $66.6 \%$, respectively.

After ADA dose reduction, 47 of the 53 (88.6\%) PsA patients and three of the $17(17.6 \%)$ RA controls maintained remission $(P=0.016)$. Psoriatic Arthritis Severity Index score dropped from $8.7 \pm 5.9$ at baseline to $3.1 \pm 1.8$ at remission 
Table I Baseline demographic, clinical characteristics, and treatment of 76 case patients and 55 controls observed over a 3-year period

\begin{tabular}{|c|c|c|c|}
\hline & $\begin{array}{l}\text { Psoriatic } \\
\text { arthritis }\end{array}$ & $\begin{array}{l}\text { Rheumatoid } \\
\text { arthritis }\end{array}$ & $P$ value \\
\hline Patient $\mathrm{N}$ & 76 & 55 & NS \\
\hline Females (N/\%) & $35(46 \%)$ & 40 (73\%) & 0.004 \\
\hline Males (N/\%) & $4 \mathrm{I}(54 \%)$ & I5 (27\%) & \\
\hline Age (years) & $46 \pm 10.2$ & $50 \pm 11.6$ & NS \\
\hline Disease duration (months) & $12 \pm 8.3$ & $16 \pm 9.6$ & NS \\
\hline $\begin{array}{l}\text { Rheumatoid factor } \\
\text { positive (N/\%) }\end{array}$ & 0 & 48 (89\%) & \\
\hline \multicolumn{4}{|l|}{ Psoriatic arthritis pattern } \\
\hline Peripheral & 45 (59\%) & & \\
\hline Axial & 7 (9\%) & & \\
\hline Mixed & $24(31.5 \%)$ & & \\
\hline Fatigue (VAS 0-100 mm) & $58 \pm 14.3$ & $62 \pm 14.9$ & NS \\
\hline Pain (VAS I-100) & $66 \pm 13.4$ & $69 \pm 10.8$ & NS \\
\hline $\begin{array}{l}\text { Articular morning stiffness } \\
\text { (minutes) }\end{array}$ & $120 \pm 46.2$ & $132 \pm 55.3$ & NS \\
\hline Tender joint count $(\mathrm{N})$ & $I I \pm 4 . I$ & $12 \pm 3.5$ & NS \\
\hline Swollen joint count $(\mathrm{N})$ & $5 \pm 2.1$ & $7 \pm 3.3$ & NS \\
\hline $\begin{array}{l}\text { Erythrocyte sedimentation } \\
\text { rate }(\mathrm{mm} / \mathrm{h})\end{array}$ & $40 \pm 15.2$ & $46 \pm 19.1$ & NS \\
\hline C-reactive protein $(\mathrm{mg} / \mathrm{dL})$ & $4.4 \pm 1.9$ & $4.9 \pm 2.2$ & NS \\
\hline $\begin{array}{l}\text { Patients with dactylitis } \\
(\mathrm{N} / \%)\end{array}$ & $10(13 \%)$ & $0(0 \%)$ & 0.014 \\
\hline $\begin{array}{l}\text { Patients with enthesitis/ } \\
\text { tenosynovitis (N/\%) }\end{array}$ & $22(29 \%)$ & $3(5 \%)$ & 0.002 \\
\hline $\begin{array}{l}\text { Patients with extra- } \\
\text { articular features (N/\%) }\end{array}$ & $8(12 \%)$ & $5(9 \%)$ & NS \\
\hline Disease activity score & $5.21 \pm 0.87$ & $5.48 \pm 0.34$ & NS \\
\hline Bath Ankylosing & $6.1 \pm 1.1$ & & \\
\hline Spondylitis Disease & & & \\
\hline Activity Index & & & \\
\hline $\begin{array}{l}\text { Psoriatic Arthritis Severity } \\
\text { Index score }\end{array}$ & $8.7 \pm 5.9$ & & \\
\hline Methotrexate (N/\%) & $64(84 \%)$ & $47(85 \%)$ & NS \\
\hline
\end{tabular}

Notes: Bath Ankylosing Spondylitis Disease Activity Index was calculated in patients with axial and mixed pattern PsA (3I patients). Except where otherwise indicated, data are expressed as mean \pm SD.

Abbreviations: N, number; NS, not significant; SD, standard deviation; VAS, visual analog scale.

$(P<0.001)$ and did not change significantly after ADA dose halving, with the mean value at the end of the follow-up period being $3.9 \pm 2.6(P=0.086)$. Disease relapse was recorded in six PsA patients - three $(9.3 \%)$ with peripheral PsA, one (20\%) with axial, and two (12.5\%) with mixed PsA patterns - with a mean time to recur of 8.3 months. As dictated by the protocol, ADA dose was increased to $40 \mathrm{mg} /$ eow in these patients, who then achieved remission again after a mean interval of $5.1 \pm 2.4$ months.

Regarding drug tolerability and safety, mild injection site reactions were recorded in $11(20.7 \%)$ patients, urinary infections in three (5.6\%), upper airways infections
Table 2 Frequency of remission in psoriatic arthritis (PsA) patients and rheumatoid arthritis (RA) controls receiving adalimumab (ADA), time to remission, and duration of remission after ADA dose reduction

\begin{tabular}{|c|c|c|c|}
\hline & $\begin{array}{l}\text { Psoriatic } \\
\text { arthritis } \\
76 \text { patients }\end{array}$ & $\begin{array}{l}\text { Rheumatoid } \\
\text { arthritis } \\
55 \text { patients }\end{array}$ & $P$ value \\
\hline Overall remission (N/\%) & $53(69.7 \%)$ & $17(30.9 \%)$ & 0.019 \\
\hline $\begin{array}{l}\text { Combined methotrexate } \\
(\mathrm{N} / \%)\end{array}$ & $46(86.7 \%)$ & 16/17 (94.1\%) & NS \\
\hline \multicolumn{4}{|l|}{ Remission by PsA pattern } \\
\hline - Peripheral & $32(71.1 \%)$ & & \\
\hline - Axial & 5 (7I.4\%) & & \\
\hline - Mixed & $16(66.6 \%)$ & & \\
\hline $\begin{array}{l}\text { Time to remission (months/ } \\
\text { mean } \pm S D \text { ) }\end{array}$ & $5.1 \pm 1.2$ & $6.3 \pm 1.6$ & NS \\
\hline $\begin{array}{l}\text { PsA remission after ADA } \\
\text { dose reduction (N/\%) }\end{array}$ & 47 (88.6\%) & $3(17.6 \%)$ & 0.016 \\
\hline \multicolumn{4}{|l|}{ Relapse by PsA pattern (N/\%) } \\
\hline - Peripheral & $3(9.3 \%)$ & & \\
\hline - Axial & I (20\%) & & \\
\hline - Mixed & $2(12.5 \%)$ & & \\
\hline $\begin{array}{l}\text { Time to relapse (months/ } \\
\text { mean } \pm S D \text { ) }\end{array}$ & $8.3 \pm 3.4$ & $7.2 \pm 4.2$ & NS \\
\hline $\begin{array}{l}\text { Duration of follow-up } \\
\text { (months/mean } \pm S D \text { ) }\end{array}$ & $28.9 \pm 8.4$ & $24.2 \pm 6.4$ & NS \\
\hline
\end{tabular}

Abbreviations: ADA, adalimumab; PsA, Psoriatic arthritis; N, number; NS, not significant; SD, standard deviation.

in $12(22.6 \%)$, and slightly elevated liver enzymes in three (5.6\%), with no severe adverse events requiring ADA interruption. Antinuclear antibodies positivity was observed in five (9.4\%) PsA patients and in six (10.9\%) controls with RA during the entire follow-up period, which was not statistically significant. No patients developed signs or symptoms of lupus-like syndromes.

\section{Discussion}

While no remission criteria have been standardized for PsA, data from several clinical series ${ }^{20-22}$ and from the British Society for Rheumatology Biologics Register ${ }^{23}$ reported a frequency of clinical remission ranging from $17.6 \%$ to $58 \%$, with the highest rate observed in patients treated with antiTNF $\alpha$ agents. This wide range may be partly explained by the absence of validated criteria for remission in PsA, which has led to the use of different sets for remission assessment, as well as the different methods of selecting patients. In a previous study,$^{16}$ we evaluated the frequency and duration of clinical remission in patients with early peripheral PsA requiring second-line drugs, adopting a restrictive set of criteria based on the absence of systemic manifestations, peripheral and axial articular symptoms (including tendons and entheses), extraarticular features, and normality of acute-phase reactants. The overall frequency of remission was $24.1 \%$, with a remission 
rate of $60.5 \%$ in patients taking anti-TNF $\alpha$ agents. In this study, a consistent percentage of subjects with PsA, treated with either traditional disease modifying anti-rheumatic drugs or anti-TNF, did not relapse over a prolonged time (mean $12 \pm 2$ months) after therapy interruption, thus suggesting an intermittent therapeutic strategy as a possible option for PsA patients achieving remission.

Since the recruitment period in the above-mentioned study preceded the approval of ADA for the treatment of PsA, none of the patients received this drug. However, the effectiveness of ADA for PsA therapy has been demonstrated in different clinical trials, ${ }^{7,9,10,24-28}$ with approximately $60 \%$ of patients achieving a good clinical response. In addition, a recent study of 152 PsA patients with long-standing disease (median 8 years) treated with ADA demonstrated a 58\% remission rate, with a significant difference with respect to the $48 \%$ rate recorded in patients with $\mathrm{RA}^{22}$

Given the evidence of the efficacy of ADA (and of all antiTNF agents in general terms) in the treatment of PsA, another important issue is the economic impact of this therapy, which has an estimated cost of around $€ 14,000 /$ patient/year. Consequently, every effort to reduce this economic burden is desirable on the condition that patient outcome and quality of life does not worsen. As we observed in a previous clinical series, ${ }^{16}$ in PsA patients achieving remission, therapy withdrawal may be a possible strategy for reducing drug-exposure risk and lowering the economic burden on public health care systems. This therapeutic approach has also been attempted in patients with RA. In a Japanese study, 52 (30.2\%) of the 172 RA patients treated with combined infliximab and MTX achieved remission. In nine of these patients, infliximab was discontinued with no recurrences over a mean follow-up period of 14.2 months. $^{29}$

In this context, we designed the present case-control study to evaluate the efficacy of ADA dose reduction in PsA patients achieving clinical remission. Over a 3-year period, according to the Group for Research and Assessment of Psoriasis and Psoriatic Arthritis recommendations, ${ }^{3}$ we treated 76 patients with active early PsA and 55 RA patients with ADA. Confirming the results of other authors, ${ }^{22}$ in our study, a significantly higher percentage of PsA patients compared with those with RA achieved clinical remission (69.7\% vs $30.9 \% ; P=0.019)$. After ADA dose reduction to $40 \mathrm{mg}$ every 4 weeks, 47 of the $53(88.6 \%)$ PsA patients maintained remission over a mean follow-up period of $28.9 \pm 8.4$ months compared with three of the $17(17.6 \%)$ RA patients $(P<0.001)$; no significant worsening of skin manifestations were found.
To the best of our knowledge, this is the first study on PsA patients that demonstrates the sustained efficacy of ADA in maintaining remission after halving the dose. A similar therapeutic strategy has been previously attempted both in RA and in ankylosing spondylitis patients. In an open-label study of 21 RA patients, infliximab dose titration using disease activity score improvement allowed for the reduction of $67 \%$ of the total amount of the drug with maintenance of clinical response. ${ }^{30}$ The sustained efficacy after halving the dose of etanercept in patients with ankylosing spondylitis has been reported in two studies. In the first, 18 patients receiving etanercept at a dose of $25 \mathrm{mg} /$ weekly were still in remission after 6 months, ${ }^{31}$ and in the second, 16 patients maintained remission after etanercept tailoring over a mean follow-up period of $26.1 \pm 21$ months. $^{32}$

The successful ADA dose halving in our PsA patients suggests two main considerations. First, none of the patients included into the present study experienced ADA-related adverse events, allowing us to speculate that dose reduction may be hypothetically associated with a long-term lower incidence of drug-related adverse events and toxicity. Second, ADA dose halving permitted a marked cost-saving effect, with an estimated savings of more than $€ 700,000$ (cost of ADA standard dose therapy/patient/month: €1166; ADA halving dose: $€ 583$ /month; multiplied by 47 patients over a mean follow-up period of 28 months).

To conclude, our results indicate that clinical remission is possible in a high percentage of patients with early PsA receiving ADA, with a significant difference with respect to those with RA. Moreover, different from patients with RA, after ADA dose reduction, a high proportion of PsA patients $(88.6 \%)$ maintained remission over a long-term follow-up period. Sustained disease remission after ADA dose halving suggests the application of this therapeutic strategy in clinical practice with important advantages in terms of drug-exposure risk and cost savings.

\section{Disclosure}

The authors have no conflicts of interest to declare.

\section{References}

1. Cantini F, Niccoli L, Nannini C, Kaloudi O, Bertoni M, Cassarà E. Psoriatic arthritis: a systematic review. Int J Rheum Dis. 2010;13(4):300-317.

2. Kammer GM, Soter NA, Gibson DJ, Schur PH. Psoriatic arthritis: a clinical, immunologic and HLA study of 100 patients. Semin Arthritis Rheum. 1979;9(2):75-97.

3. Ritchlin CT, Kavanaugh A, Gladman DD, et al. Treatment recommendations for psoriatic arthritis. Ann Rheum Dis. 2009;68(9):1387-1394.

4. Salvarani C, Pipitone N, Marchesoni A, et al. Recommendations for the use of biologic therapy in the treatment of psoriatic arthritis: update from the Italian Society for Rheumatology. Clin Exp Rheumatol. 2011; 29(3 Suppl 66):S28-S41. 
5. Mease PJ, Goffe BS, Metz J, et al. Etanercept in the treatment of psoriatic arthritis and psoriasis: a randomised trial. Lancet. 2000;356(9227): 385-390.

6. Antoni CE, Kavanaugh A, Kirkham B, et al. Sustained benefits of infliximab therapy for dermatologic and articular manifestations of psoriatic arthritis: results from the infliximab multinational psoriatic arthritis controlled trial (IMPACT). Arthritis Rheum. 2005;52(4):1227-1236.

7. Mease PJ, Gladman DD, Ritchlin CT, et al. Adalimumab for the treatment of patients with moderately to severely active psoriatic arthritis: results of a double-blind, randomized, placebo-controlled trial. Arthritis Rheum. 2005;52(10):3279-3289.

8. Kavanaugh A, McInnes I, Mease P, et al. Golimumab, a new human tumor necrosis factor alpha antibody, administered every four weeks as a subcutaneous injection in psoriatic arthritis: twenty-four-week efficacy and safety results of a randomized, placebo-controlled study. Arthritis Rheum. 2009;60(4):976-986.

9. Gladman DD, Mease PJ, Ritchlin CT, et al. Adalimumab for long-term treatment of psoriatic arthritis: forty-eight week data from the adalimumab effectiveness in psoriatic arthritis trial. Arthritis Rheum. 2007; 56(2):476-488.

10. Mease PJ, Ory P, Sharp JT, et al. Adalimumab for long-term treatment of psoriatic arthritis: 2-year data from the Adalimumab Effectiveness in Psoriatic Arthritis Trial (ADEPT). Ann Rheum Dis. 2009;68(5): 702-709.

11. Taylor WJ, Gladman D, Helliwell P, et al. Classification Criteria for Psoriatic Arthritis. Development of New Criteria From a Large International Study. Arthritis Rheum. 2006;54(8):2665-2673.

12. Arnett FC, Edworthy SM, Bloch DA, et al. The American Rheumatism Association 1987 revised criteria for the classification of rheumatoid arthritis. Arthritis Rheum. 1988;31(3):315-324.

13. Van der Linden S, Valkenburg HA, Cats A. Evaluation of diagnostic criteria for ankylosing spondylitis: a proposal for modification of the New York criteria. Arthritis Rheum. 1984;27(4):361-368.

14. Heuft-Dorenbosch L, Spoorenberg A, van Tubergen A, et al. Assessment of enthesitis in ankylosing spondylitis. Ann Rheum Dis. 2003;62(2):127-132.

15. Calin A, porta J, Fries JF, Schurman DJ. Clinical history as a screening test for ankylosing spondylitis. JAMA. 1977;237(24):2613-2614.

16. Cantini F, Niccoli L, Nannini C, et al. Frequency and duration of clinical remission in patients with peripheral arthritis requiring second-line drugs. Rheumatology (Oxford). 2008;47(6):872-876.

17. Garrett S, Ienkinson T, Kennedy G, Whitelock H, Gaisford P, Calin A. A new approach to defining disease status in ankylosing spondylitis: the Bath ankylosing spondylitis disease activity index. $J$ Rheumatol. 1994;21(12):2286-2291.

18. Fransen J, Creemers MC, Van Riel PL. Remission in rheumatoid arthritis: agreement of the disease activity score (DAS28) with the ARA preliminary remission criteria. Rheumatology (Oxford). 2004;43(10): $1252-1255$.

19. Fredriksson T, Pettersson U. Severe psoriasis - oral therapy with a new retinoid. Dermatologica. 1978;157(4):238-244.
20. Kane D, Stafford L, Bresnihan B, Fitzgerald O. A prospective, clinical and radiological study of early psoriatic arthritis: an early synovitis clinic experience. Rheumatology (Oxford). 2003;42(12):1460-1468.

21. Gladman DD, Tung Hing ENG, Schentag CT, Cook RJ. Remission in Psoriatic arthritis. J Rheumatol. 2001;28(5):1045-1048.

22. Saber TP, Ng CT, Renard G, et al. Remission in psoriatic arthritis: is it possible and how can it be predicted? Arthritis Res Ther. 2010; 12(3):R94.

23. Saad AA, Ashcroft DM, Watson KD, Symmons DPM, Noyce PR, Hyrich KL. Efficacy and safety of anti-TNF therapies in psoriatic arthritis: an observational study from the British Society for Rheumatology Biologics Register. Rheumatology. 2010;49(4):697-705.

24. Genovese MC, Mease PJ, Thomson GT, et al. Safety and efficacy of adalimumab in treatment of patients with psoriatic arthritis who had failed disease modifying antirheumatic drug therapy. J Rheumatol. 2007;34(5):1040-1050.

25. Van den Bosch F, Manger B, Goupille P, et al. Effectiveness of adalimumab in treating patients with active psoriatic arthritis and predictors of good clinical responses for arthritis, skin and nail lesions. Ann Rheum Dis. 2010;69(2):394-399.

26. Atteno M, Peluso R, Costa L, et al. Comparison of effectiveness and safety of infliximab, etanercept, and adalimumab in psoriatic arthritis patients who experienced an inadequate response to previous disease-modifying antirheumatic drugs. Clin Rheumatol. 2010;29(4): 399-403.

27. Gladman DD; ACCLAIM Study Investigators, Sampalis JS, Illouz $\mathrm{O}$, Guérette B. Responses to adalimumab in patients with active psoriatic arthritis who have not adequately responded to prior therapy: effectiveness and safety results from an open-label study. J Rheumatol. 2010;37(9):1898-1906.

28. Scarpa R, Atteno M, Lubrano E, et al. The effectiveness and safety of TNF-alpha blockers in the treatment of early psoriatic arthritis: an Italian multicentre longitudinal observational pilot study. Clin Rheumatol. 2011;30(8):1063-1067.

29. Nawata M, Saito K, Nakayamada S, Tanaka Y. Discontinuation of infliximab in rheumatoid arthritis patients in clinical remission. Mod Rheumatol. 2008;18(5):460-464.

30. den Broeder AA, Creemers MCW, van Gestel AM, vanRiel PLCM. Dose titration using the Disease Activity Score (DAS28) in rheumatoid arthritis patients treated with anti-TNF- $\alpha$. Rheumatology. 2002;41(6): 638-642.

31. Lee SH, Lee YA, Hong SJ, Yang HI. Etanercept $25 \mathrm{mg} /$ week is effective enough to maintain remission for ankylosing spondylitis among Korean patients. Clin Rheumatol. 2008;27(2):179-181.

32. Navarro-Compán V, Moreira V, Ariza-Ariza R, Hernández-Cruz B, Vargas-Lebrón C, Navarro-Sarabia F. Low doses of etanercept can be effective in ankylosing spondylitis patients who achieve remission of the disease. Clin Rheumatol. 2011;30(7):993-996.
Biologics: Targets \& Therapy

\section{Publish your work in this journal}

Biologics: Targets \& Therapy is an international, peer-reviewed journal focusing on the patho-physiological rationale for and clinical application of Biologic agents in the management of autoimmune diseases, cancers or other pathologies where a molecular target can be identified. This journal is indexed on PubMed Central, CAS, EMBase, Scopus

\section{Dovepress}

and the Elsevier Bibliographic databases. The manuscript management system is completely online and includes a very quick and fair peerreview system, which is all easy to use. Visit http://www.dovepress com/testimonials.php to read real quotes from published authors. 